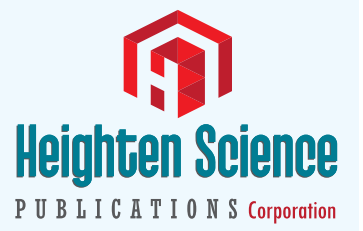

ISSN

2639-9946

\title{
Upper gut bacterial overgrowth is a potential mechanism for Glucose Malabsorption after Vertical Sleeve Gastrectomy
}

\author{
Matthew E Sharbaugh ${ }^{1}$, Timothy R Shope ${ }^{1,2}$ and Timothy R Koch ${ }^{1,2 *}$ \\ 'Department of Surgery, Georgetown University School of Medicine, Washington, DC 20010, \\ USA \\ ${ }^{2}$ Center for Advanced Laparoscopic General \& Bariatric Surgery, MedStar Washington Hospital \\ Center and Georgetown University School of Medicine, Washington, DC 20010, USA
}

\begin{abstract}
*Address for Correspondence: Timothy R Koch, MD, Professor of Medicine (Gastroenterology), Georgetown University School of Medicine, Center for Advanced Laparoscopic General \& Bariatric Surgery, POB South, Suite 301, MedStar Washington Hospital Center, 110 Irving Street, NW, Washington, DC 20010, USA, Tel: +1-202 8777788; Fax: +1-877 6808198; Email: timothy.r.koch@medstar.net
\end{abstract}

Submitted: 20 October 2017

Approved: 30 October 2017

Published: 31 October 2017

Copyright: @ 2017 Sharbaugh ME, et al . This is an open access article distributed under the Creative Commons Attribution License, which permits unrestricted use, distribution, and reproduction in any medium, provided the original work is properly cited.

Keywords: Morbid obesity; Bariatrics; Bariatric surgery; Vertical sleeve gastrectomy; Diabetes mellitus

Check for updates

\section{Summary}

In 1955, nutrient malabsorption following upper gut surgery was shown to be related to altered upper gut microbiome. In individuals with abdominal symptoms after Roux-en-Y gastric bypass, we have reported that small intestinal glucose malabsorption is associated with upper gut bacterial overgrowth. We hypothesize that individuals with abdominal symptoms after vertical sleeve gastrectomy have glucose malabsorption associated with upper gut bacterial overgrowth, and to test this hypothesis, bacterial overgrowth and potential glucose malabsorption are examined after sleeve gastrectomy. This is a retrospective study of individuals with medicallycomplicated obesity who underwent sleeve gastrectomy from 2013 to 2016 with subsequent glucose hydrogen breath testing to evaluate abdominal symptoms. A fasting breath hydrogen or methane of $\geq 10$ PPM or rise of $\geq 8$ $\mathrm{PPM} \leq 45$ minutes after oral glucose is bacterial overgrowth, while glucose malabsorption is a second rise of $\geq 8$ PPM at $>45$ minutes. Seven females (mean age: 48.0 years; mean body mass index at surgery: $45.7 \mathrm{~kg} / \mathrm{m}^{2}$ ) are described. Five subjects $(71 \%)$ have an early rise in hydrogen or methane, while three $(43 \%)$ have a second rise in hydrogen or methane $>45$ minutes after glucose. The mean percent excess weight loss at one year was $40 \%$ in three individuals with a second peak and $46 \%$ in four subjects without a second peak. After sleeve gastrectomy, subjects have glucose malabsorption associated with the presence of bacterial overgrowth. Completion of a larger prospective study is needed to confirm and expanding upon these findings. Further work should examine the potential effects of bacterial overgrowth on expression of intestinal glucose transporters.

\section{Introduction}

In a recent international study involving 195 countries, the prevalence of obesity has reportedly doubled since 1980 in more than 70 countries with an estimated 107.7 million obese children and 603.7 million obese adults in 2015 [1]. The rapid rise in the prevalence of obesity has created a global health crisis. Laparoscopic vertical sleeve gastrectomy (LapVSG) has been recognized as an effective surgical option for the management of medically-complicated obesity. From 2011 to 2015, LapVSG gained the forefront of bariatric surgical procedures performed in the United States, and has replaced Roux-en-Y gastric bypass (RYGB) as the most common surgical treatment of medically-complicated obesity [2]. Indeed, LapVSG has gained international acceptance as an effective surgical option for treatment of medically-complicated obesity [3].

In 1955, Dr. JA Halsted described micronutrient malabsorption (e.g. vitamin B12 deficiency) following upper gut surgery associated with an altered upper gut microbiome [4], now termed small intestinal bacterial overgrowth or SIBO. Our previous work reported finding vitamin B1 deficiency in those individuals with SIBO after RYGB [5]. In a follow up study of individuals with abdominal symptoms after 
RYGB, glucose hydrogen breath testing was used to examine the presence of SIBO and the potential malabsorption of glucose [6]. Small intestinal glucose malabsorption was found to be associated with the presence of SIBO [6].

Based upon these prior studies, we hypothesize that individuals with abdominal symptoms after LapVSG also have glucose malabsorption associated with SIBO. Our aims in this present study are to determine whether there is SIBO after VSG, whether there is glucose malabsorption after VSG, whether there is an association between SIBO and glucose malabsorption, and whether glucose malabsorption may alter weight loss after LapVSG.

\section{Methods}

\section{Subjects}

This human study was approved by the Human Studies Subcommittee of MedStar Research Institute (Hyattsville, MD) on December 14, 2016. Because this was determined to be a minimal risk protocol by the Human Studies Subcommittee, a waiver of informed consent was granted for this research study. This is a single institution, retrospective study completed in our large, urban community teaching hospital. This is a retrospective study of patients with medically-complicated obesity who underwent LapVSG as we have previously described [7] and had glucose (25 grams) hydrogen breath testing for evaluation of abdominal symptoms. LapVSG is mainly a restrictive procedure in which the gastric fundus and body are surgically excised thus resulting in a narrow, lesser-curvature based stomach (Figure 1).

Each individual's demographic information, the preoperative presence of diabetes mellitus, the percentage of excess body weight loss (we subtracted the individual's postoperative weight from their preoperative weight, divided that number by their preoperative excess weight, and then multiplied that result by 100) at 1 year after LapVSG, the results of glucose breath testing, and the time period between bariatric surgery and glucose hydrogen breath testing are recorded.

\section{Glucose hydrogen breath testing}

The performance of glucose- hydrogen/methane breath testing in individuals after bariatric surgery has been described [6]. No antibiotic use was permitted for 1 month before the breath test. Individuals present for breath testing after an overnight 12 hour fast prior to the procedure. Using a breath microlyzer (Quintron Instrument Company, Milwaukee, WI), baseline end expiratory values of breath hydrogen and methane are obtained. Each subject receives a solution containing 25 grams of glucose dissolved in $240 \mathrm{ml}$ of water, which is then ingested orally. The dose of glucose has been limited in our clinical laboratory to 25 grams since post-bariatric patients commonly complain of marked abdominal pain and/or diarrhea after receiving a 50 gram dose of glucose. Breath hydrogen concentrations and methane concentrations are then measured every 15 minutes for 2 hours after ingestion of glucose. Based upon a previous study [8] that described at least a 10 parts per million rise in breath hydrogen after 75

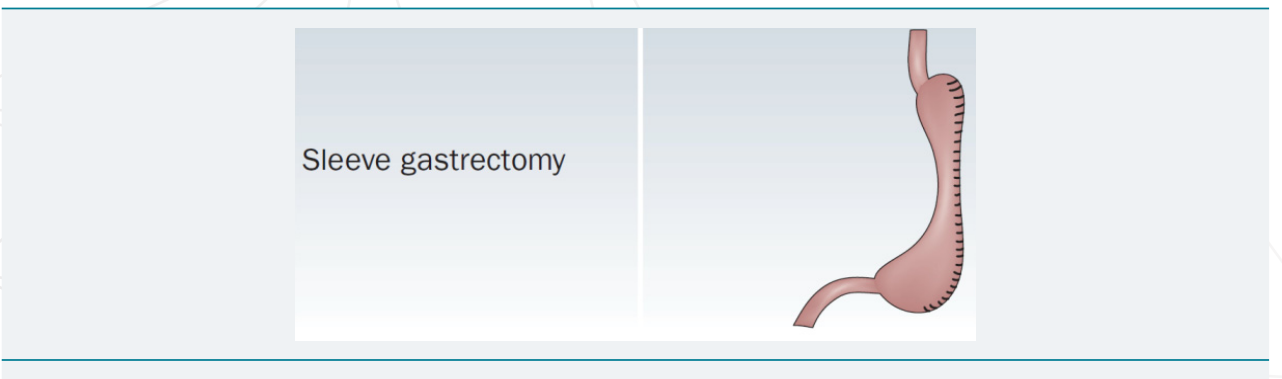

Figure 1: Anatomical cartoon depicting the result from a vertical sleeve gastrectomy; the gastric fundus and body have been surgically excised, thus resulting in a narrow, lesser-curvature based stomach [7]. 
grams of glucose in individuals with $\geq 10^{6}$ colony forming units $/ \mathrm{ml}$ in jejunal aspirates, upper gut bacterial overgrowth is considered to be diagnosed by either a fasting breath hydrogen or methane of $\geq 10$ parts per million or a rise of $\geq 8$ parts per million $\leq 45$ minutes after ingestion of 25 grams of glucose. An early rise in breath hydrogen or methane is accepted as reflecting glucose fermentation by bacteria in the upper gastrointestinal tract. Glucose malabsorption was defined by a second rise of $\geq 8$ parts per million hydrogen or methane at $>45$ minutes after glucose. The late rise in breath hydrogen or methane is accepted to be consistent with glucose reaching the terminal ileum or entering the colon and thus being metabolized by ileocolonic flora. If there is an early rise in breath hydrogen, a later rise in breath methane is not accepted as consistent with glucose malabsorption due to the potential for production of methane from hydrogen by intraluminal bacteria. Figure 2 demonstrates the typical findings in an individual with both an early and a late rise in breath hydrogen/methane.

\section{Statistical Analysis}

Statistical analysis was performed using a standardized computer program (StatView; SAS Institute Inc, Cary, NC). A p value $<0.05$ was considered to be significant.

\section{Results}

\section{Demographics}

Seven females are included in this study with a mean age of 48.0 years-old (range: 35 to 57 years) and a mean body mass index at the day of bariatric surgery of $45.7 \mathrm{~kg} /$ $\mathrm{m}^{2}$ (range: 40 to $53 \mathrm{~kg} / \mathrm{m}^{2}$ ). The mean time from surgery until glucose hydrogen breath testing was 692 days (range: 307 to 1344 days).

\section{Glucose hydrogen breath test}

Figure 3 demonstrates the breath test results for these seven individuals after LapVSG. Five subjects $(71 \%)$ had either an elevated fasting hydrogen/methane or an early rise in hydrogen or methane, and these findings are consistent with upper gut bacterial overgrowth. Three subjects (50\%) had a rise in hydrogen or methane $>45$ minutes after glucose ingestion, consistent with glucose malabsorption. None of these three individuals had preoperative diabetes mellitus. However, all three of these subjects also demonstrated an early rise in breath hydrogen or methane $\leq 45$ minutes after ingestion of 25 grams of glucose. As shown in the $2 \times 2$ table 1, these findings did not reach statistical significance.

REPRESENTATIVE GLUCOSE (25 g) BREATH TEST

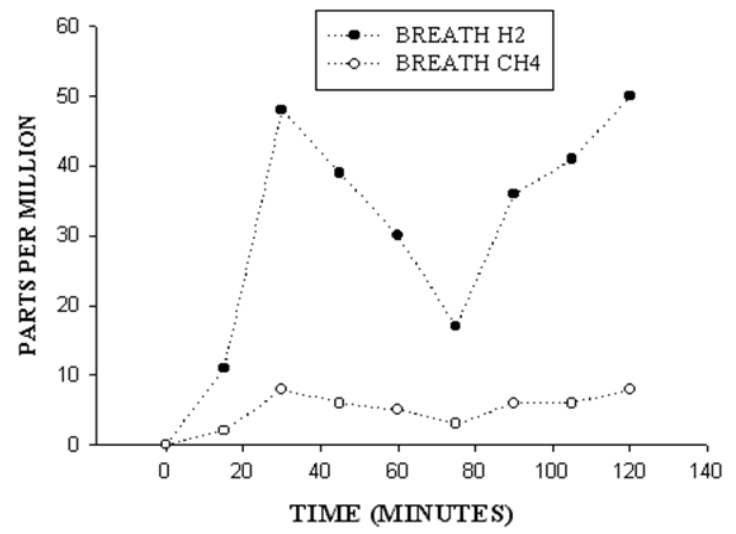

Figure 2: Breath hydrogen (closed circles) and methane (open circles) were measured in parts per million at time 0 and then at 15 minutes intervals for 2 hours. After the fasting breath value at time 0 , the subject was given 25 grams of glucose to drink. This graph shows a typical rise in breath hydrogen in a subject with two peaks: the first peak is consistent with upper gut bacterial overgrowth and the second peak is consistent with glucose malabsorption. 


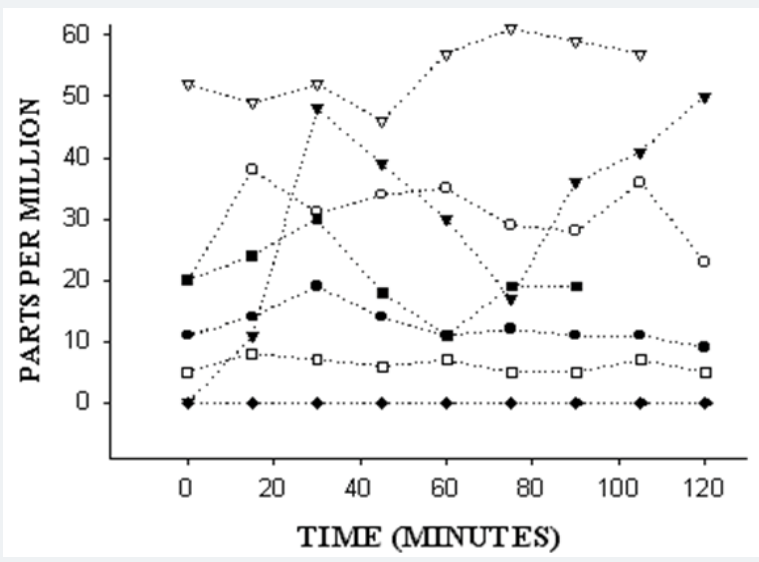

Figure 3: Breath test results for seven individuals after laparoscopic vertical sleeve gastrectomy. The $y$-axis represents breath values in parts per million at time 0 and then at 15 minutes intervals for 2 hours. On the x-axis, after the fasting breath value at time 0 , each subject was given 25 grams of glucose to drink. Five of the seven subjects have an elevated resting breath test or a rise after ingestion of 25 grams of glucose, supporting the presence of upper gut bacterial overgrowth.

Table 1: Subjects with a Significant Early or a Late Rise in Breath Hydrogen or Methane.

\begin{tabular}{|c|c|c|c|}
\hline \multicolumn{4}{|c|}{ Late Rise } \\
\hline & & Yes & No \\
\hline Early & Yes & 3 & 2 \\
\hline Rise & No & 0 & 2 \\
\hline
\end{tabular}

\section{Weight loss}

The average percent excess weight loss at one year was $40 \%$ in three subjects with a second peak and $46 \%$ in four subjects without a second peak ( $p>0.05)$.

\section{Discussion}

This feasibility study supports our hypothesis that individuals after LapVSG develop glucose malabsorption associated with the presence of upper gut bacteria. In this small study, we saw no evidence for increased percent excess weight loss in individuals who have evidence on glucose hydrogen breath testing for glucose malabsorption. There is however a dearth of information with regards to upper gut bacterial overgrowth in individuals after vertical sleeve gastrectomy, and so this study extends our prior study of the role of upper gut bacterial overgrowth after RYGB [6]. Upper gut bacterial overgrowth could induce glucose malabsorption by altering the function of small intestinal glucose transporters. There is a sodium-dependent glucose cotransporter (SGLT1) at the apical membrane of the small bowel enterocyte $[9,10]$. At the basolateral side of the enterocyte membrane, a second glucose transporter termed GLUT2 has been identified and GLUT2 has been thought to be important for the process of simple glucose diffusion $[10,11]$. There is presently minimal information about the potential role of upper gut bacteria in altering the expression or function of enterocyte proteins.

Glucose malabsorption after bariatric surgery is an interesting potential origin for postoperative weight loss. Presently proposed mechanisms of weight loss after LapVSG include restriction of dietary intake of calories and a reduction in the release of the orexigenic hormone, ghrelin [12]. As a potential secondary role of glucose malabsorption, a number of potential mechanisms have been proposed to be involved in the improvement of glycemic control after bariatric surgery including changes in secretion of gastrointestinal hormones, bacterial flora, bile acids, intestinal gluconeogenesis, gastrointestinal motility, and a potential role for adipose tissue in the production of inflammatory mediators [13]. 
The major weakness of this present study is the concern about the potential for rapid transit of glucose to the terminal ileum or cecum. It has been reported from the Medical College of Wisconsin in Milwaukee, WI that glucose commonly reaches the cecum during a breath test [14]. In their study, upper GI surgery was defined as surgery involving the esophagus, stomach, or small bowel. Among 54 patients with upper GI surgery, $30 \%$ of these patients had evidence for passage of glucose to the cecum. Their result appears similar to the $43 \%$ of individuals that our present study has identified as having evidence for glucose malabsorption after LapVSG. In the Milwaukee study, however, the authors used 80 grams of glucose compared to the smaller dose of 25 grams of glucose that we use. It was also not clear whether the tracer that was used for scintigraphy (Tc-99m diethylenetriaminepentaacetic acid) altered small bowel motility. Small bowel transit could be validated using other methods including small intestinal follow through $\mathrm{x}$-rays with barium or studies of small intestinal capsule endoscopy.

Studies of small bowel motility after LapVSG have utilized liquid ingestion, semisolid meals, and solid meals. In a study of liquid ingestion of 75 grams of glucose after LapVSG, small bowel transit was estimated by cine MRI scans and it appeared that transit to the terminal ileum was accelerated postoperatively [15]. An important result of this study was that the authors appeared to demonstrate that glucose was reaching the terminal ileum after LapVSG and thus glucose was not being absorbed. Using scintigraphy with a radiolabeled semisolid meal, it has been reported that LapVSG results in both a more rapid duodenum to terminal ileum transit time as well as delayed cecal filling [16]. It is difficult to know how these two opposite processes might alter small intestinal glucose absorption. In a third study, small bowel transit time after LapVSG as estimated by scintigraphy following ingestion of a radiolabeled solid meal was reported to be 199.6+/-65.7 minutes [17]. This third study does not support rapid oral-cecal transit after LapVSG.

In summary, this study provides evidence that individuals after LapVSG have glucose malabsorption associated with the presence of upper gut bacterial overgrowth. Completion of a larger prospective study will be important for confirming and expanding upon these present findings and hypothesis. Further work is needed to examine the potential effects of upper gut bacterial overgrowth on expression of small intestinal glucose transporters.

\section{References}

1. GBD 2015 Obesity Collaborators, Afshin A, Forouzanfar MH, Reitsma MB, Sur P, et al. Health effects of overweight and obesity in 195 countries over 25 years. N Engl J Med. 2017; 377: 13-27. Ref.: https://goo.gl/oxyjxc

2. American Society for Metabolic and Bariatric Surgery. Estimate of Bariatric Surgery Numbers, 2011 2015. 2016. Ref.: https://goo.gl/UkDJuc

3. Angrisani L, Santonicola A, lovino P, Formisano G, Buchwald H, et al. Bariatric Surgery Worldwide 2013. Obesity Surg. 2015; 25: 1822-1832. Ref.: https://goo.gl/u6NJ76

4. Halsted JA. Megaloblastic anemia, associated with surgically produced gastrointestinal abnormalities. Calif Med. 1955; 83: 212-217. Ref.: https://goo.gl/MrvpMR

5. Lakhani SV, Shah HN, Alexander K, Finelli FC, Kirkpatrick JR, et al. Small intestinal bacterial overgrowth and thiamine deficiency after Roux-en-Y gastric bypass surgery in obese patients. Nutr Res. 2008; 28: 293-298. Ref.: https://goo.gl/d9wG7C

6. Andalib I, Shah H, Bal BS, Shope TR, Finelli FC, et al. Breath hydrogen as a biomarker for glucose malabsorption after Roux-en-Y gastric bypass surgery. Dis Markers. 2015. Ref.: https://goo.gl/yUVLSu

7. Nath A, Yewale S, Tran T, Brebbia JS, Shope TR, et al. Dysphagia after vertical sleeve gastrectomy Evaluation of risks factors and assessment of endoscopic intervention. World J Gastroenterol. 2016; 22: 10371-10379. Ref.: https://goo.gl/dBGfvR 
8. Corazza GR, Menozzi MG, Strocchi A, Rasciti L, Vaira D, et al. The diagnosis of small bowel bacterial overgrowth. Reliability of jejunal culture and inadequacy of breath hydrogen testing. Gastroenterology. 1990; 98: 302-309. Ref.: https://goo.gl/9ZMyLh

9. Malathi $\mathrm{P}$, Preiser $\mathrm{H}$. Isolation of the sodium-dependent d-glucose transport protein from brushborder membranes. Biochim Biophys Acta. 1983; 735: 314-324. Ref.: https://goo.gl/iYG9R1

10. Hamilton KL, Butt AG. Glucose transport into everted sacs of the small intestine of mice. Adv Physiol Educ. 2013; 37: 415-426. Ref.: https://goo.gl/64R1M4

11. Thorens B. Molecular and cellular physiology of GLUT-2, a high-Km facilitated diffusion glucose transporter. Int Rev Cytol. 1992; 137: 209-238. Ref.: https://goo.gl/19UEzW

12. Rashti F, Gupta E, Ebrahimi S, Shope TR, Koch TR, et al. Development of minimally invasive techniques for management of medically-complicated obesity. World J Gastroenterol. 2014; 20: 13424-13445. Ref.: https://goo.gl/2B4QjQ

13. Yamamoto $\mathrm{H}$, Kaida S, Yamaguchi T, Murata S, Tani M, et al. Potential mechanisms mediating improved glycemic control after bariatric/metabolic surgery. Surg Today. 2016; 46: 268-274. Ref.: https://goo.gl/jRr7rb

14. Lin EC, Massey BT. Scintigraphy demonstrates high rate of false-positive results from glucose breath tests for small bowel bacterial overgrowth. Clin Gastroenterol Hepatol. 2016; 14: 203-208. Ref.: https://goo.gl/EPCp4P

15. Trung VN, Yamamoto H, Furukawa A, Yamaguchi T, Murata S, et al. Enhanced intestinal motility during oral glucose tolerance test after laparoscopic sleeve gastrectomy: Preliminary results using cine magnetic resonance imaging. 2013; 8: 65739. Ref.: https://goo.gl/2zh9Ha

16. Melissas J, Leventi A, Klinaki I, Perisinakis K, Koukouraki S, et al. Alterations of global gastrointestinal motility after sleeve gastrectomy: a prospective study. Ann Surg. 2013; 258: 976-982. Ref.: https://goo.gl/PB6mxz

17. Shah S, Shah P, Todkar J, Gagner M, Sonar S, et al. Prospective controlled study of effect of laparoscopic sleeve gastrectomy on small bowel transit time and gastric emptying half-time in morbidly obese patients with type 2 diabetes mellitus. Surg Obes Relat Dis. 2010; 6: 152-157. Ref.: https://goo.gl/Wccquc 